\title{
Pushing back the cliff (but there probably still is a cliff): Arrhythmia, late outcome, and uncertainty in Fontan patients
}

\author{
Mark E. Alexander, MD, FHRS
}

\footnotetext{
From the Arrhythmia Service, Department of Cardiology, Boston Children's Hospital; and Department of Pediatrics, Harvard Medical School, Boston, Mass.

Disclosures: Author has nothing to disclose with regard to commercial support.

Received for publication Aug 11, 2016; accepted for publication Aug 15, 2016; available ahead of print Sept 17, 2016.

Address for reprints: Mark E. Alexander, MD, FHRS, Arrhythmia Service, Department of Cardiology, Boston Children's Hospital, 300 Longwood Ave, Boston, MA 02115 (E-mail: Mark.alexander@ cardio.chboston.org). J Thorac Cardiovasc Surg 2016;152:1364-5 $0022-5223 / \$ 36.00$

Copyright (c) 2016 by The American Association for Thoracic Surgery http://dx.doi.org/10.1016/j.jtcvs.2016.08.030
}

Nearly 50 years ago, the Fontan procedure accelerated the development of modern congenital heart care. In exchange for eliminating cyanosis and protecting the pulmonary vasculature, there are long-term risks attributed to Fontan physiology and operative technique of tachy- and bradyarrhythmias, hepatic complications from elevated venous pressure, protein-losing enteropathy, and plastic bronchitis. Important associated issues of ventricular and valve dysfunction each contribute to worsening of Fontan physiology. These, of course, may be a consequence of underlying anatomic vulnerability.

Yves D'Udekem ${ }^{1}$ from Melbourne and the accomplished team of surgeons and cardiologists who care for these patients in Australia and New Zealand have taken advantage of their combination of a stable patient cohort and relatively limited number of specialist centers to create a productive ongoing registry of Fontan outcomes. In this analysis, they focus on the role arrhythmias have in predicting outcomes. The figures and tables cut to the critical aspects of their findings. Figure 1 reminds us of the nearly monotonic increase in tachyarrhythmia prevalence. Jumping to Figure 2 and Table 4, they demonstrate that both tachycardia and bradycardia are powerful predictors of Fontan failure or a composite outcome of death/transplant (although notably not of death).

The data are then analyzed on the basis of the conditional risks from the time of first arrhythmia. Although the risks of poor outcomes clearly increase, that fall-off is not that rapid, with $70 \%$ of patients with arrhythmia alive 15 years after initial arrhythmia. Simple cardioversion offered a median of 2 years of relief. Ablation offered benefit of up to 10 years in $50 \%$ of the patients.

Although these data strongly support the development of arrhythmia as a marker to identifying patients at risk of Fontan failure, caution continues to be needed in the use of arrhythmia as an early indication for Fontan revision. These data do not specify the precise nature of Fontan failure, and when Fontan revision is triggered by arrhythmia the outcome (even if correct!) becomes self-fulfilling. Furthermore, what would the revision be when the initial procedure

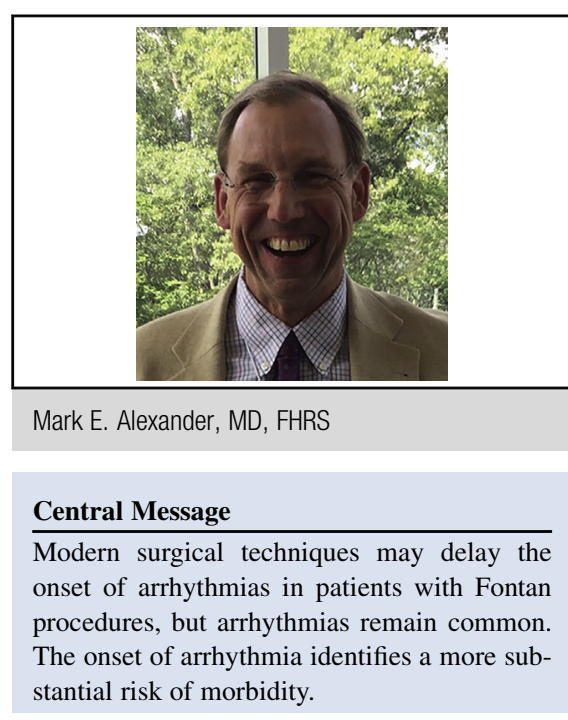

See Article page 1355 .

was already an extracardiac Fontan? The complex risks of that procedure continue to keep decisions regarding Fontan revisions challenging. ${ }^{2}$

The data are weaker on identifying both surgical and physiologic contributors to development of arrhythmias. Although decreased ventricular function was common, in $43 \%$ of those with tachyarrhythmia and $69 \%$ of those with pacemakers, the role of ventricular function in predicting arrhythmias or the interaction between ventricular function and arrhythmia is not analyzed in a substantive way.

Despite the powerful $P$ values, these data are neither a convincing endorsement of the extracardiac Fontan nor a rejection of the lateral tunnel. These groups were early and relatively consistent adopters of the extracardiac Fontan. That practice pattern represents one of the more significant limitations of these data. Patients with arrhythmias were substantially older (26 vs 14), had longer follow-up, and were much more likely to have had an atriopulmonary connection. Appendix Figure B highlights the follow-up limitation of the modern extracardiac techniques with an abrupt end to the follow-up curve, similar to the limitations of the analysis by the Pediatric Heart Network. ${ }^{3,4}$ That analysis showed no difference between the techniques. The systematic limitations in follow-up duration and the other effects of surgical era continue to limit our ability to declare a "victor" in that debate. It does remind the electrophysiologist that he or she needs to master the techniques of entering the pulmonary venous atrium in these patients. 
Figure 2 emphasizes the core messages of these data. The presence of any arrhythmia is a powerful predictor of future Fontan failure. Old-style atriopulmonary Fontan procedures are worse than modern techniques. Both lateral tunnel and extracardiac techniques delay and decrease but do not prevent tachy- or bradyarrhythmias. This is better than 20 years ago. ${ }^{6}$ Alas, as we get 15-20 years away from an event any risk number calculated only has weak precision of $\pm 25 \%-30 \%$. This of course, is where the morbidity starts to really increase and follow-up is more diffuse. That reality means we look forward to this group continuing to enhance our understanding of how our changing management decisions can aid our patients.

\section{References}

1. Carins TA, Shi WY, Iyengar AJ, Nisbet A, Forsdick V, Zannino D, et al. Long-term outcomes after first-onset arrhythmia in Fontan physiology. J Thoracic Cardiovasc Surg. 2016;152:1355-63.e1

2. Takahashi K, Fynn-Thompson F, Cecchin F, Khairy P, del Nido P, Triedman JK Clinical outcomes of Fontan conversion surgery with and without associated arrhythmia intervention. Int J Cardiol. 2009;137:260-6.

3. Oechslin EN, Harrison DA, Connelly MS, Webb GD, Siu SC. Mode of death in adults with congenital heart disease. Am J Cardiol. 2000;86:1111-6.

4. Stephenson EA, Lu M, Berul CI, Etheridge SP, Idriss SF, Margossian R, et al Arrhythmias in a contemporary fontan cohort: prevalence and clinical associations in a multicenter cross-sectional study. J Am Coll Cardiol. 2010;56:890-6.

5. Moore JP, Shannon KM, Fish FA, Seslar SP, Garnreiter JM, Krause U, et al. Catheter ablation of supraventricular tachyarrhythmia after extracardiac Fontan surgery. Heart Rhythm. 2016;13:1891-7.

6. Fishberger SB, Wernovsky G, Gentles TL, Gauvreau K, Burnett J, Mayer JE Jr, Walsh EP. Factors that influence the development of atrial flutter after the Fontan operation. J Thorac Cardiovasc Surg. 1997;113:80-6. 